\title{
Diagnostic role of bronchoalveolar lavage: A cytohistopathological correlation
}

\author{
Prabesh Kumar Choudhary ${ }^{1}$, Niraj Nepal ${ }^{1}$, Ram Hari Ghimire ${ }^{2}$, Nirajan Mainali ${ }^{1}$ \\ ${ }^{I}$ Department of Pathology, Nobel Medical College Teaching Hospital and Research Centre, Biratnagar, Nepal. \\ ${ }^{2}$ Department of Pulmonology, Nobel Medical College and Teaching Hospital and Research Centre, Biratnagar, Nepal
}

\section{Keywords:}

Adenocarcinoma; Brochoalveolar lavage; Bronchogenic; Carcinoma; Lung;

\section{ABSTRACT}

Background: Tumors of lung are common in Nepal. The risk of malignancy has to be judged prior to surgery for which bronchoscopy is often done. Brocho-alveolar lavage and bronchial biopsy are routine procedure done for diagnosis of lung cancer during bronchoscopy. This study was done to correlate the cytology of broncho-alveolar lavage specimen with histopathology in malignant tumors of the lug in our setup.

Materials and methods: This study was conducted at department of pathology, Nobel Medical College from August 2017 to December 2018. Histopathology reports with malignancy were compared to their cytological diagnosis.

Results: A total of 141 cases were included in the study. Among the study population, Bronchogenic carcinoma was found more prevalent in female. The sensitivity, specificity, positive predictive value, negative predictive value and overall accuracy of broncho-alveolar lavage in the diagnosis of lung cancer were $88.1 \%, 97.98 \%, 94.7 \%, 95.1 \%$ and $95.03 \%$ respectively.

Conclusions: Brochoalveolar lavage cytology has a greater accuracy for the diagnosis of lung cancer; however, benign cases need regular follow up as there are false negative cases.

\section{Correspondence:}

Dr. Prabesh Kumar Choudhary, MD

Department of Pathology

Nobel Medical College Teaching Hospital and Research Centre

Biratnagar, Nepal.

ORCID ID: 0000-0001-7431-5820

Email: khushbudev.dev@gmail.com

Received : January $4^{\text {th }} 2019 ;$ Accepted : March $2^{\text {nd }} 2019$; Published : March $29^{\text {th }} 2019$

Citation: Choudhary PK, Nepal N, Ghimire RH, Mainali N. Diagnostic role of broncho-alveolar lavage: A cyto-histopathological correlation. J Pathol. Nep 2019;9:1441-4. DOI: 10.3126/jpn. v9i1.23173

Copyright: This is an open-access article distributed under the terms of the Creative Commons Attribution 4.0 International License, which permits unrestricted use, distribution, and reproduction in any medium, provided the original author and source are credited.

\section{INTRODUCTION}

Diseases of the lung are very common in Nepal. Common ones include pneumonia, tuberculosis, chronic obstructive pulmonary disease (COPD), and neoplastic conditions which includes benign and malignant tumors. Malignant lung lesions have incidence rate of $4.45 \%$ in male in Nepal among all the malignant condition. ${ }^{1}$ Common malignant tumor of lung includes squamous cell carcinoma, adenocarcinoma, small cell carcinoma and neuroendocrine carcinoma. $^{2}$

Bronchoscopy is a minimally invasive, cost-effective, OPD 
based, procedure which allows examination of bronchial tree as far as distal lung parenchyma. Moreover, it has increased the variety of specimens that can be obtained during the procedure and includes, broncho-alveolar lavage (BAL), bronchial brush, bronchial biopsy and trans-bronchial needle aspiration. Broncho-alveolar lavage is still being used as the first line of diagnostic tool for the evaluation of malignant lung lesions. Further, it has many cytological utilities and can even guide in treatment planning without having bronchial biopsy. ${ }^{3}$ Bronchial biopsy is still considered as the most sensitive diagnostic tool and moreover, it has highest accuracy in determining the definite histological type. ${ }^{4,5}$ Hence, BAL has emerged as important alternative tool in obtaining a diagnosis.

In view of important role of BAL and mere paucity of such study in our state, this study was planned with the primary objective of correlating the BAL cytology with bronchial biopsy, taking later as the gold standard diagnostic test for malignant lung tumor.

\section{MATERIALS AND METHODS}

This was a prospective cross sectional study conducted from August 2017 to December 2018 at Nobel Medical College and Teaching Hospital (NMCTH). Ethical clearance was taken from institutional review committee. All patients having clinical and radiological suspicion of malignancy were included in this study. Informed consent was taken in all cases. Cases having contraindication for bronchial biopsy and in cases with inadequate samples were excluded from the study.

The obtained BAL specimen was fixed in ethyl alcohol and later centrifuged at 1500 revolutions per minute. Three smears made from cell concentrate and were stained with May-Grünwald-Giemsa (MGG) and Papanicolaou (Pap) stains as per the standard guidelines. Smears having few cells or cell details, obscured by blood, and degenerative changes and artifacts were excluded from this study. Smears having inadequate number of macrophages $(<10$ alveolar macrophages/10 high power fields) were also not included in this study. Smears were examined by three pathologists and were categorized in to benign, suspicious for malignancy, and malignant. All inflammatory conditions and smears having benign cytological features were considered in benign category. Smears having some dysplasia not enough to consider it malignant were considered suspicious for malignancy. Smears having obvious cytological features of malignancy were considered malignant lesion. An attempt to categorize the type of malignancy was done in every case.

All bronchial biopsy specimens were fixed in 10\% formalin and processed on automated tissue processor. Paraffin embedded sections were stained by hematoxylin and eosin stain. Lesions were classified into benign and malignant based upon the histological findings. Further, histological typing of tumor was also done.

All data were inserted in SPSS 17 software. Histopathological report was considered as the gold standard. For statistical analysis, suspicious of malignancy and malignant categories were considered cytologically malignant. Cytological report was correlated with histopathological diagnosis. Diagnostic accuracy of BAL was obtained by following formulas:

Sensitivity $=\mathrm{TP} / \mathrm{TP}+\mathrm{FN} \times 100 \quad \mathrm{TP}=$ True positive
Specificity $=\mathrm{TN} / \mathrm{TN}+\mathrm{FP} \times 100 \quad \mathrm{TN}=$ True negative
Positive predictive value $(\mathrm{PPV})=\mathrm{TP} / \mathrm{TP}+\mathrm{FP} \times 100$
$\mathrm{FP}=$ False positive

Negative predictive value $(\mathrm{NPV})=\mathrm{TN} / \mathrm{TN}+\mathrm{FN} \times 100$ $\mathrm{FN}=$ False negative

Accuracy $=\mathrm{TP}+\mathrm{TP} /$ Total number of cases $\mathrm{x} 100$

\section{RESULTS}

A total of 141 cases were included in the study. Among them $88(62.4 \%)$ were male and $53(37.6 \%)$ with a male to female ratio of 1.6:1. Age of the patients ranged from 52 to 94 years and median age of 67 years.

Cytological diagnosis and histopathological diagnosis is shown in table 1. In BAL cytology; Benign lesions were $102(72.3 \%)$ followed by $36(25.5 \%)$ malignant lesions. Histopathological diagnosis was benign 99 (70.2\%) and $42(29.7 \%)$ were malignant lesions. (Table 1) Among 42 malignant cases diagnosed in biopsy specimen; squamous cell carcinoma was the most common malignancy $(n=20$;

Table 1: Comparison of Cytological diagnosis with final histopathology $(n=141)$

\begin{tabular}{|c|c|c|c|c|}
\hline $\begin{array}{c}\text { Cytological } \\
\text { Diagnosis }\end{array}$ & Number & Histopathological Diagnosis & Number & Remarks \\
\hline \multirow{2}{*}{ Benign } & \multirow{2}{*}{102} & Benign & 97 & $\mathrm{TN}$ \\
\hline & & Malignant & 05 & FN \\
\hline \multirow{2}{*}{$\begin{array}{l}\text { Suspicious of } \\
\text { Malignancy }\end{array}$} & \multirow{2}{*}{03} & Benign & 01 & $\mathrm{FP}$ \\
\hline & & Malignant & 02 & TP \\
\hline \multirow{2}{*}{ Malignant } & \multirow{2}{*}{36} & Benign & 01 & FP \\
\hline & & Malignant & 35 & $\mathrm{TP}$ \\
\hline
\end{tabular}


Table 2: Distribution of histopathological diagnosis of malignant tumor

\begin{tabular}{lc}
\hline Histopathological Diagnosis & Number (\%) \\
\hline Squamous cell carcinoma & $20(47.6 \%)$ \\
\hline Adenocarcinoma & $18(42.8 \%)$ \\
\hline Small cell carcinoma & $02(4.7 \%)$ \\
\hline Large cell carcinoma & $01(2.4 \%)$ \\
\hline Other & $01(2.4 \%)$ \\
\hline Total & $\mathbf{4 2 ( 1 0 0 \% )}$ \\
\hline
\end{tabular}

47.6\%) followed by adenocarcinoma $(n=18 ; 42.8 \%)$. (Table 2)

The BAL cytology correctly identifies 97 (95.1\%) of benign, 01(33.33\%) of suspicious for malignancy and 35 (94.8\%) of malignant cases. The sensitivity, specificity, positive predictive value, negative predictive value and overall accuracy of BAL were $88.1 \%, 97.98 \%, 94.7 \%, 95.1 \%$ and $95.03 \%$ respectively. Five cases $(4.9 \%)$ were considered falsely as benign lesions. Similarly, 2 benign cases were over-diagnosed as suspicious of malignancy and malignant lesion.

\section{DISCUSSION}

Early diagnosis and treatment of lung cancer has been always critical. Broncho-alveolar cytology is an easy minimally invasive procedure and has been well tolerated by patients. Various combination assays are available to improve the diagnostic precision of the BAL cytology, but this does mean that the BAL alone is invaluable. Bronchoalveolar lavage has always been an important procedure for clinicians who manage patients in whom lung cancer is suspected. This study was conducted to determine the accuracy of BAL cytology using histopathological diagnosis as gold standard in the diagnosis of lung carcinoma at our centre.

Squamous cell carcinoma was the most common malignant tumor in our study. Similar finding was also observed by Ahmed $\mathrm{A}$ et al. ${ }^{4}$ In contrast, Binesh $\mathrm{F}$ et al found adenocarcinoma as the most common malignant tumor. ${ }^{6}$

Our study had a sensitivity of $88.1 \%$ which is similar to the study done by Ahmed et al. ${ }^{4}$ In contrast, sensitivity was only $69.1 \%$ and $48.6 \%$ in a study done by Pradeep et $\mathrm{al}^{7}$ and Tang et al. $^{8}$ These discrepancies may be explained by sampling error or the presence of benign process that mimics malignancy.

False positivity in benign conditions and false negativity in the early stage of malignant conditions are the primary limitations of BAL examination. These drawbacks could be due to poor distribution of BAL specimens, infrequent exfoliation of malignant cells and interpretive errors. Cytological sampling by BAL relies mainly on cells exfoliated from tumors. It is well known that some lung tumors, for unknown reasons, do not exfoliate diagnostic cells regardless of number of specimens collected.

In this study $1.4 \%$ false positivity rate was encountered. Common factors responsible for false positive results include misinterpretation of the cytological findings due to reactive cellular changes in inflammatory diseases, squamous metaplasia and epithelial cell atypia in the background of fibrosis. Two out of 3 suspicious for malignancy cases turned to be malignant in biopsy report. False positivity was also negligible in studies done by Ahmed et $\mathrm{al}^{4}$ and Pradeep et al. ${ }^{7}$ Similarly, no false positivity was found by Lachman et $\mathrm{al}^{9}$ and Rennard et al. ${ }^{10}$ These results suggest that false positivity is rare and is thus a great advantage of BAL cytology.

False negativity was $3.5 \%$ in this study which is in contrast to $6.5 \%$ found by Ahmed et al. ${ }^{4}$ Wongsurakiat et $\mathrm{al}^{11}$ had a significant false negative result. The main factors contributing to false negative cases can be confounding inflammation, non representative specimen or hypocellular lavage.

A positive predictive value of $94.7 \%$ and negative predictive value of $95.1 \%$ was comparable to Ahmed et al and Binesh F et al. ${ }^{4,6}$

Statistical analysis in our study revealed a sensitivity, specificity, positive predictive value, negative predictive value and accuracy of $88.1 \%, 97.98 \%, 94.7 \%, 95.1 \%$ and $95.03 \%$ respectively. These results were comparable to the others where the BAL has reported sensitivity ranging from $60 \%$ to $99 \%$, specificity $80 \%$ to $100 \%$, positive predictive value $85 \%$ to $97 \%$, negative predictive value $88 \%$ to $99 \%$ and accuracy $89 \%$ to $99 \% .4,6,12$ These varied results may be due to number of cases, subjective errors and sampling errors. The overall accuracy of $95.03 \%$ in our study certainly confirms the diagnostic role of BAL in the diagnosis of lung cancer.

\section{CONCLUSION}

Bronchioalveolar lavage has a greater accuracy and therefore we recommend routine use of BAL for the diagnosis of lung cancer.However, non-malignant cytological interpretation should be viewed with caution as there are false negative cases and thus these cases should undergo regular clinicoradiological follow up to look for any progression that will require repeat bronchoscopy.

\section{Conflict of interest: None}

\section{REFERENCES}

1. Poudel KK, Huang Z, Neupane PR. Trend of Cancer Incidence in Nepal from 2003 to 2012. Asian Pacific journal of cancer 
prevention : APJCP. 2016;17:2171-5. https://doi.org/10.7314/ APJCP.2016.17.4.2171

2. Travis W.D., Brambilla E., Muller-Hermelink H.K., Harris C.C. (Eds.): World Health Organization Classification of Tumours. Pathology and Genetics of Tumours of the Lung, Pleura, Thymus and Heart. IARC Press: Lyon 2004. 344p

3. Jones AM, Hanson IM, Armstrong GR, O'Driscoll BR. Value and accuracy of cytology in addition to histology in the diagnosis of lung cancer at flexible bronchoscopy. Respir med. 2001;95:374-8. https:// doi.org/10.1053/rmed.2001.1051

4. Ahmed A, Ahmed S. Comparison of bronchoalveolar lavage cytology and transbronchial biopsy in the diagnosis of carcinoma of lung. J Ayub Med Coll Abbottabad. 2004;16:29-33. PMid:15762059

5. Cataluna JJ, Perpina M, Greses JV, Calvo V, Padilla JD, Paris F. Cell type accuracy of bronchial biopsy specimens in primary lung cancer. Chest. 1996;109:1199-203. https://doi.org/10.1378/chest.109.5.1199

6. Binesh F, Pirdehghan A, Mirjalili MR, Samet M, Majomerd ZA, Akhavan A. Comparative assessment of the diagnostic value of transbronchial lung biopsy and bronchoalveolar lavage fluid cytology in lung cancer. Asian Pac J Cancer Prev. 2015;16:201-4. https://doi. org/10.7314/APJCP.2015.16.1.201
7. Pradeep Kumar L RK, Srinivasa Murthy G, E A. Comparison of effectiveness of BAL [bronchoalveolar lavage] with CT Guided FNAC in the diagnosis of lung cancer. J Evolu Med Dental Sci, 2014;11:2752-6.

8. Tang CC, Hsiao CJ, Chen $\mathrm{H}$, et al. Value of bronchoalveolar lavage combined with transbronchial lung biopsy in the diagnosis of peripheral lung cancer. Chang Gung Med J. 2000;23:695-700. PMid:11190379

9. Stephen I. Rennard. Bronchoalveolar lavage in the diagnosis of cancer. Lung. 1990;168:1035-40. https://doi.org/10.1007/BF02718241

10. Lachman MF SK, Cellura K. Bronchoscopic diagnosis of malignancy in the lower airway. A cytologic review. Acta cytologica. 1995;39:1148-51. PMid:7483990

11. Wongsurakiat $\mathrm{P}$, Wongbunnate $\mathrm{S}$, Dejsomritrutai W, et al. Diagnostic value of bronchoalveolar lavage and postbronchoscopic sputum cytology in peripheral lung cancer. Respirology. 1998;3:131-7. https://doi.org/10.1111/j.1440-1843.1998.tb00111.x

12. Bezel $\mathrm{P}$, Tischler $\mathrm{V}$, Robinson $\mathrm{C}$ et al. Diagnostic Value of Bronchoalveolar Lavage for Diagnosis of Suspected Peripheral Lung Cancer. Clinical lung cancer. 2016;17:e151-e6. https://doi. org/10.1016/j.cllc.2015.12.012 